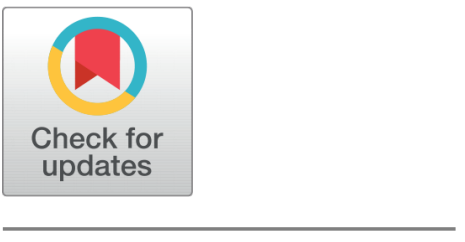

OPEN ACCESS

Received: 13.07 .2020

Accepted: 07.10 .2020

Published: 22.10 .2020

Editor: Dr. Natarajan Gajendran

Citation: Chavan SB, Chavan MS (2020) Simulation paradigm to study circuit performance in presence of component level fault. Indian Journal of Science and Technology 13(38): 3983-3993. https://doi.org/ 10.17485/IJST/v13i38.1140

* Corresponding author.

Tel: 91 - 9975490278

sbc_tech@unishivaji.ac.in

Funding: None

Competing Interests: None

Copyright: (c) 2020 Chavan \& Chavan. This is an open access article distributed under the terms of the Creative Commons Attribution License, which permits unrestricted use, distribution, and reproduction in any medium, provided the original author and source are credited.

Published By Indian Society for Education and Environment (iSee)

ISSN

Print: 0974-6846

Electronic: 0974-5645

\section{Simulation paradigm to study circuit performance in presence of component level fault}

\author{
Shamkumar B Chavan ${ }^{1 *}$, Mahesh S Chavan ${ }^{2}$ \\ 1 Department of Technology, Shivaji University, Kolhapur, 416004, Maharashtra, India. \\ Tel.: 91- 9975490278 \\ 2 KIT's College of Engineering, Gokul Shirgaon, Kolhapur, 416013, Maharashtra, India
}

\section{Abstract}

Objectives: To study the use of simulation tool to understand the circuit behavior in presence of faulty component and use of part stress method for failure rate computation. Methods/ statistical analysis: The behavior of circuit under test (CUT) is studied in normal and faulty conditions using MATLAB simulation tool. Diode open circuit and short circuit faults are separately introduced to study the circuit performance. In developed prototype real faulty diode is purposely connected to verify the performance. After that reliability computation, part failure rates of components are estimated using military handbook MIL-HDBK- $217 \mathrm{~F}$ of the CUT. Findings: In this work, a method is presented in which circuit performance in presence of faulty component is studied and individual component failure rates are estimated for reliability understanding. Close match in results of simulation tool and hardware prototype is observed. Such approach is good choice for understanding the behavior of power electronics circuit. Novelty/Applications: The proposed technique is useful in fault modeling of power supplies and power stations. Semiconductor power electronics devices are prone to failure, therefore reliability oriented designs of power supplies, converters, inverters and other power converting circuits is important issue. The component failure rates and circuit reliability should be estimated by using part stress method or suitable reliability estimating software. Individual component failure rates provide idea about long lasting behavior; fault precursors and fault signatures help to understand the circuit performance in presence of faulty component.

Keywords: Component level fault study; simulation based fault diagnosis; simulation based fault signatures; component failure rate estimation; diode fault in rectifier

\section{Introduction}

This communication describes the application of simulation tool as a paradigm to study the effect of component level fault on circuit behavior, further the estimation of failure rate is performed for the same circuit. For reliability based design aspects, designers should possess knowledge of root cause of fault, component level faults, fault precursors, 
fault signatures etc. Simulation tools are of great importance to understand the fault information. In this manuscript open circuit and short circuit faults of rectifier diode are simulated to understand the working of full bridge rectifier in faulty condition. In laboratory faulty open and short circuit diodes are selected and experimentation is performed. Simulation and experimental results are compared and verified. The approach presented here is helpful to create awareness regarding reliability issues in power electronic circuits.

Under-graduate study focus on circuit analysis and design issues while design for reliability aspect is neglected. Reliability improvement of power electronic systems is of great importance. Several surveys have suggested that power semiconductor devices, electrolytic capacitors, inductors etc. are prone to failure. This section discusses few selected articles based on reliability improvement, fault diagnosis; fault tolerant approaches on power electronics devices. A survey was conducted ${ }^{(1)}$ to check reliability aspects of power electronic converters. This survey was conducted for converters working in various atmospheric conditions, at different frequencies and at different power levels. The respondents of this survey highlighted that power semiconductor devices, electrolytic capacitors, gate drivers etc. are prone to failure. Respondents of this survey expected use of better fault diagnosing, online fault monitoring and fault tolerant systems. Uses of coolants, heat sink, redundancy based fault tolerant schemes are some of the practices used nowadays. Reference ${ }^{(2)}$ surveyed and studied the power electronics systems reliability, their assessment methods and fault tolerant methods by algorithmic solutions, redundancy approaches etc. According to authors, reliability, failure rate, MTTF (mean time to failure), MTTR (mean time to repair), availability, and average availability as metrics for reliability assessment of power electronic systems. Author says that system reliability can be improved by thermal management, better fault diagnosing and tolerant mechanisms. For fault diagnosis voltage, current in normal state and in faulty state should be monitored and compared. According to ${ }^{(3)}$ Physics of Failure (PoF) based approach for power semiconductor devices should be focused for reliability improvement. Authors depicts that there is a lack of systematic approach for reliability improvement. Some of the factors like temperature cycling, device material, manufacturing technology, quality, environmental factors etc. should be focused. Lack of design for reliability approach, uncertain strength of components, unawareness of failure mechanisms are some of the challenges in reliability oriented design while on line condition monitoring systems, knowledge of physics of failure, control on heat flow, fault tolerant designs, use of CAD tools etc. are practices in reliable power electronics systems design. $\mathrm{In}^{(4)}$ it is stated that Physics of Failure approach is based on root cause failure analysis and effect of material, stress etc. on the device. Reference ${ }^{(5)}$ presented challenges and problems in photovoltaic power processing circuits. Author says that environmental factors like humidity, temperature variations, transients etc. affect the performance of BOS module. Use of model based approach for fault diagnosis in converter of PV system is discussed ${ }^{(6)}$. References ${ }^{(7-11)}$ present redundancy based fault diagnosis and tolerant strategies for reliability improvement. Reliability oriented experimentation is discussed $^{(12)}$, in these authors stated that reliability issue is not focused in academia. Various faults and detecting techniques in power circuits of PV systems are described in ${ }^{(13)}$. MATLAB based ANN model is presented for complex mixed analog and digital CMOS circuit for prediction of accurate behavior prior to implementation, according to authors this is reliable and less time consuming solution ${ }^{(14)}$. The aim of this article is to create awareness among the beginners, practicing engineers regarding the use of simulation models to analyze the circuit behavior in presence of component level fault. Here full bridge rectifier is simulated in SimPower Systems tool box of MATLAB 2013b, diode open circuit and short circuit faults are introduced in model and circuit behavior is studied. Laboratory experimentation is performed by selecting faulty diodes. Close agreement is found in simulation and experimentation results.

\section{Materials and Method}

In this experiment full bridge rectifier circuit is taken under test.

1. The behavior of circuit in normal mode is simulated in MATLAB 2013b software.

2. Laboratory prototype is developed and experiment is performed in normal mode.

3. In simulation model diode open circuit and diode short circuit faults are manually introduced and circuit behavior is observed.

4. In hardware prototype faulty diodes are selected and connected and the circuit performance is monitored.

5. Close agreement is tested in simulation and experimental results done in laboratory.

6. Failure rate estimation of entire circuit is performed to know its reliability. Different components can be selected and their failure rates can be estimated. Based on comparison reliability oriented design can be formed. 


\subsection{Normal Working Mode}

Figure 1 shows the full bridge rectifier. In working condition, during positive half cycle diodes D3 and D2 conduct hence current passes through D3-Ro-D2 while in negative half cycle current passes through D4-Ro-D1. Pulsating DC current of frequency $2 \mathrm{f}$ passes through Ro as shown in Figure 3. Figure 2 shows the model built in SimPowerSystems toolbox of MATLAB 2013b for simulation purpose.

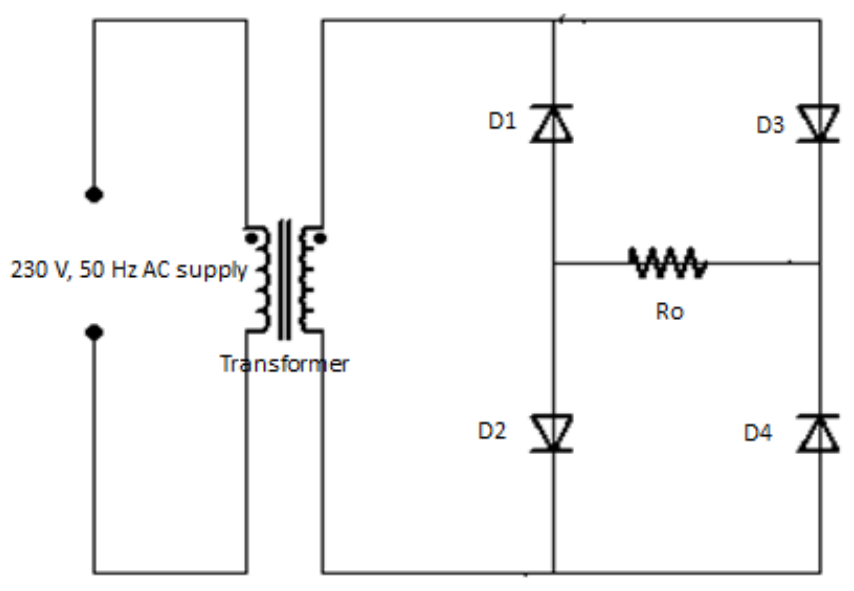

Fig 1. Full bridge rectifier

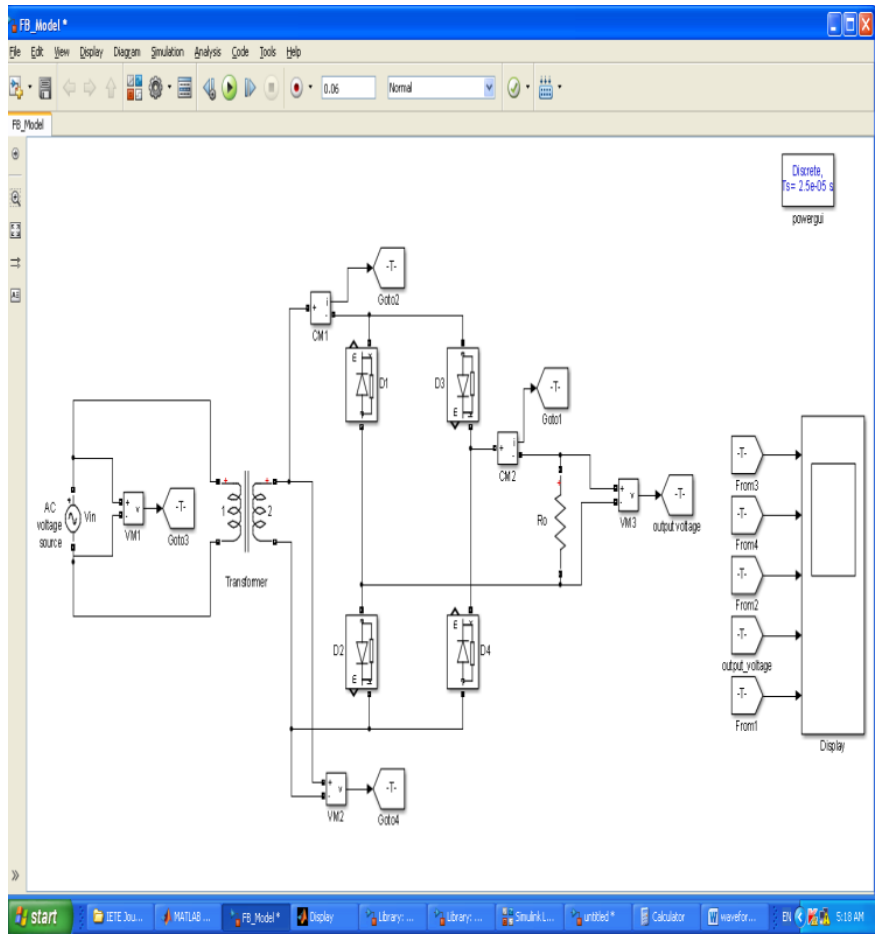

Fig 2. Simulation model developed in MATLAB 2013b 


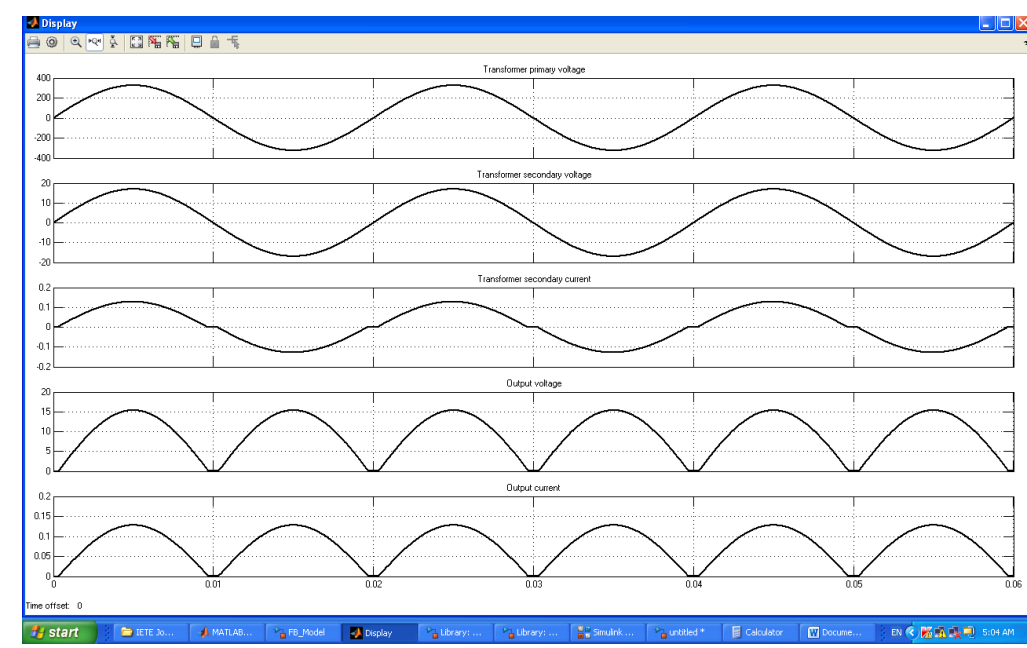

Fig 3. Waveforms in normal working condition a) Transformer primary voltage b) Transformer secondary voltage c) Transformer secondary current d) output DC voltage across load e) output DC current through load.

\subsection{Effect of Component Failure}

From literature review it is clear that electronic components are prone to failure due to several reasons like transients, over voltage, atmospheric conditions, improper handling etc. For applications requiring higher reliability CAD based simulation tool like MATLAB is powerful source to study the effect of component fault on overall working of the circuit. The expected faults can be simulated and effects due to their presence can be studied in initial design phase. This section deals with analyzing the effect of diode fault on the behavior of full bridge rectifier. Since diode is prone to two types of failures viz. open circuit and short circuit, in this model performance of rectifier circuit is studied in presence of these faults. Diode open and short circuit faults are introduced in the simulation model; experimentation is performed on prototype developed in laboratory by selecting real faulty diodes. The experimentation is limited to understand the circuit behavior in faulty state only.

\subsection{Diode Open Circuit Fault}

Diode D1 is an open circuited ( Figure 4 ) and MATLAB model is created as shown in Figure 5. In this case, during positive half cycle current passes through D3-Ro-D2 and in negative half cycle no current passes through Ro as diode D1 is open. Waveforms in negative half cycle are absent which can be seen in results obtained in simulation shown in Figure 6.

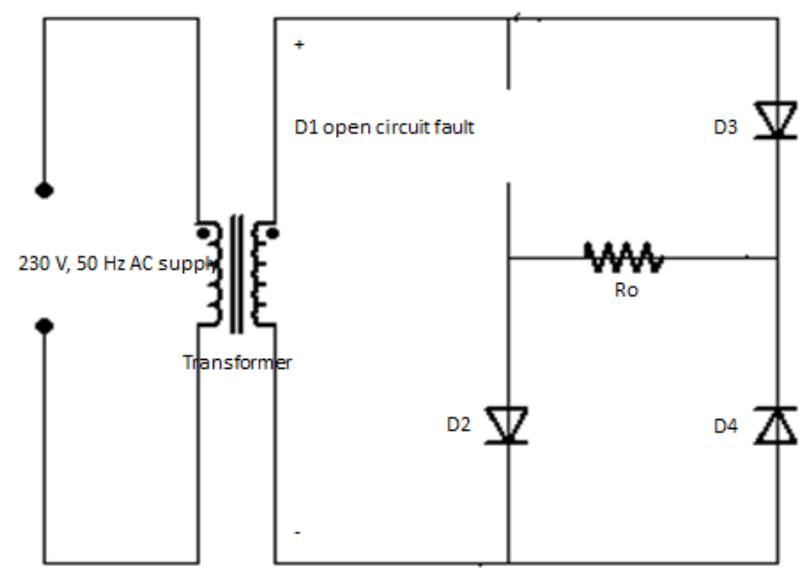

Fig 4. Diode open circuit fault 


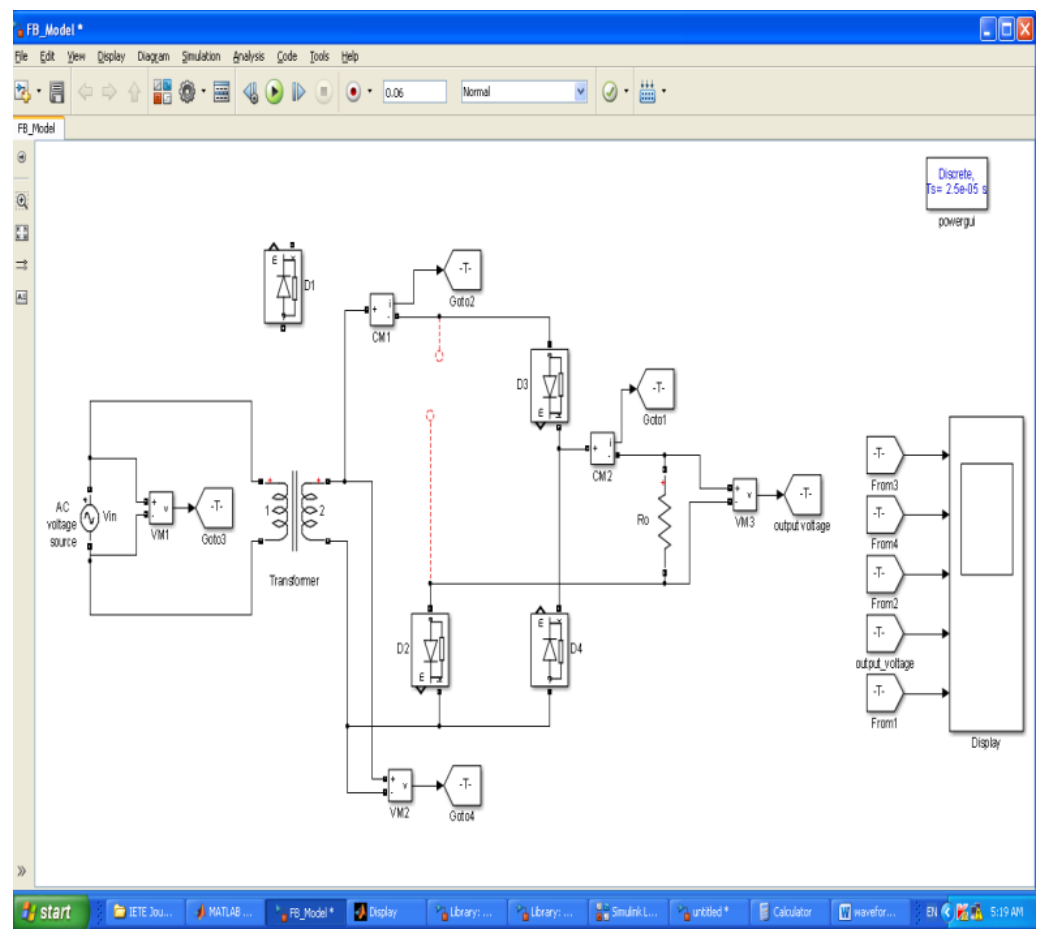

Fig 5. Simulated model for diode D1 open circuit

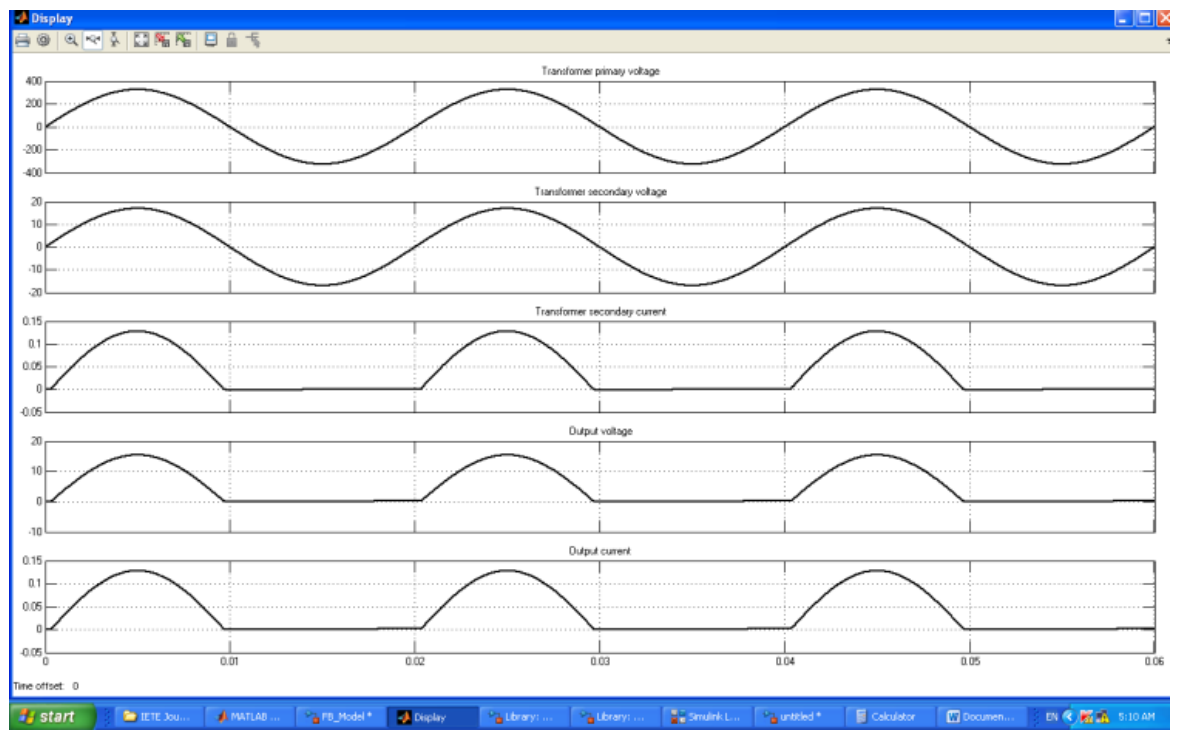

Fig 6. Waveforms obtained when diode D1 is open circuit

\subsection{Diode Short Circuit Fault}

Figure 7 shows diode D1 short circuit condition, the simulated model is shown in Figure 8. During positive half cycle current passes only through D2. Hence, during this period current through Ro is zero. During negative half cycle current passes through D4-Ro- short diode D1. From Figure 9 it is clear that current is passing through load in negative half cycle.

For short circuit diode its forward resistance $\mathrm{Rf}$ is zero. 


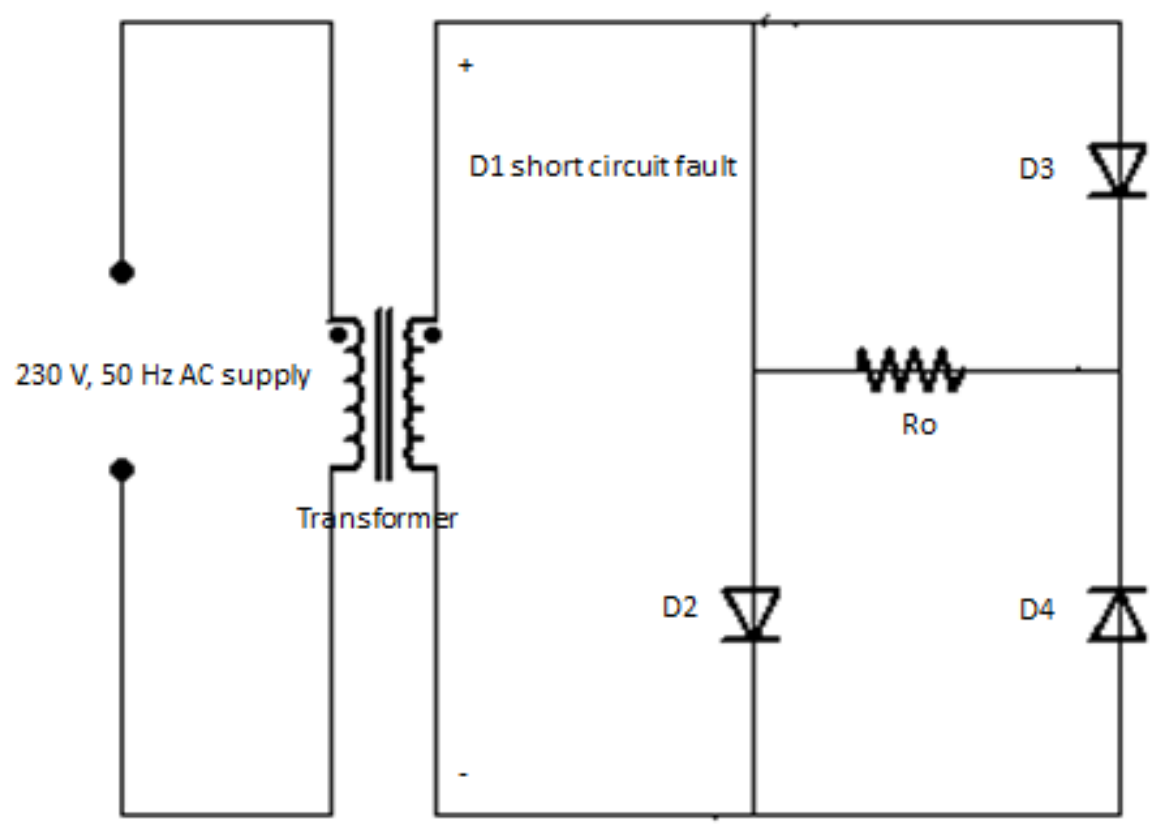

Fig 7. Diode D1 short circuit

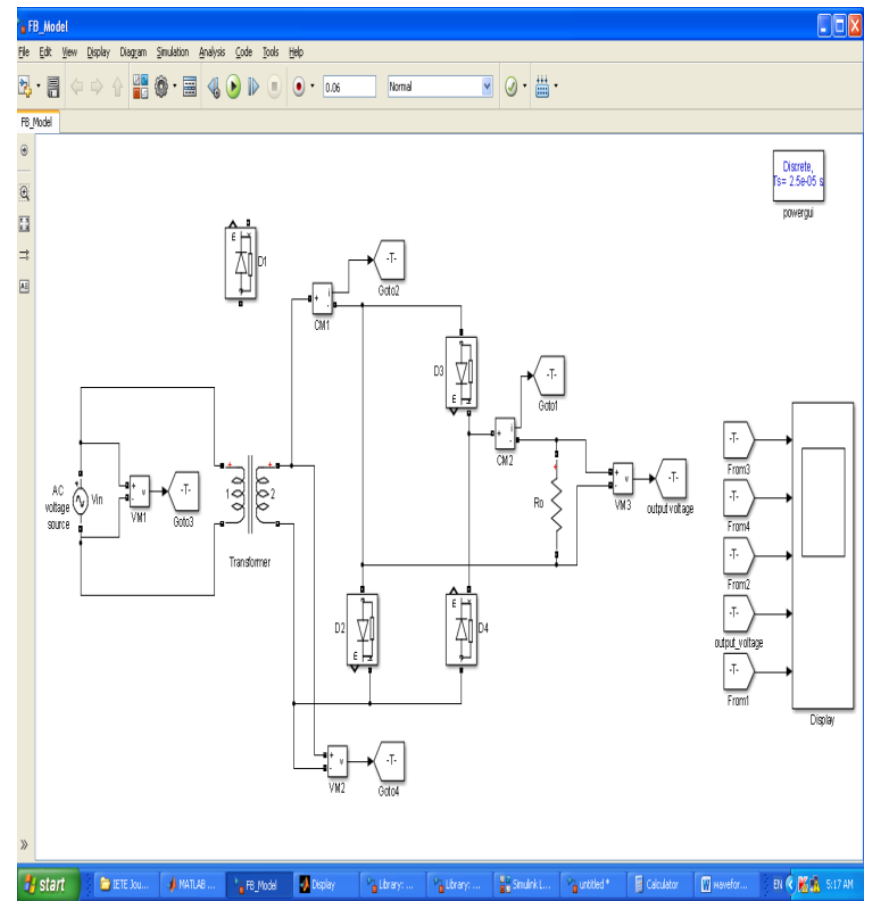

Fig 8. Model for diode D1 short circuit 


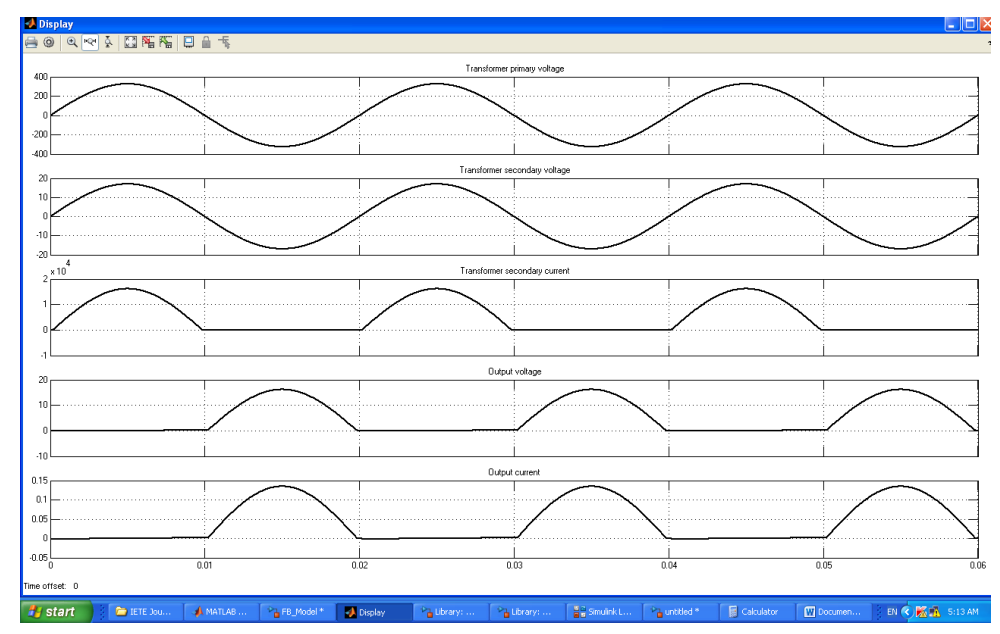

Fig 9. Waveforms for diode D1 short circuit

\section{Results and Discussion}

In this experimentation only diode $\mathrm{D} 1$ is considered as faulty and results are presented however simulation and experimentation can be extended to other components as well. The experimentation is performed by selecting open and short circuit faulty diodes in laboratory. Close agreement between simulation and experimental results is observed. Diode short and open circuit faults can be monitored in continuity test as shown in Figure 11. The experimental setup in laboratory is shown in Figures 10 and 11

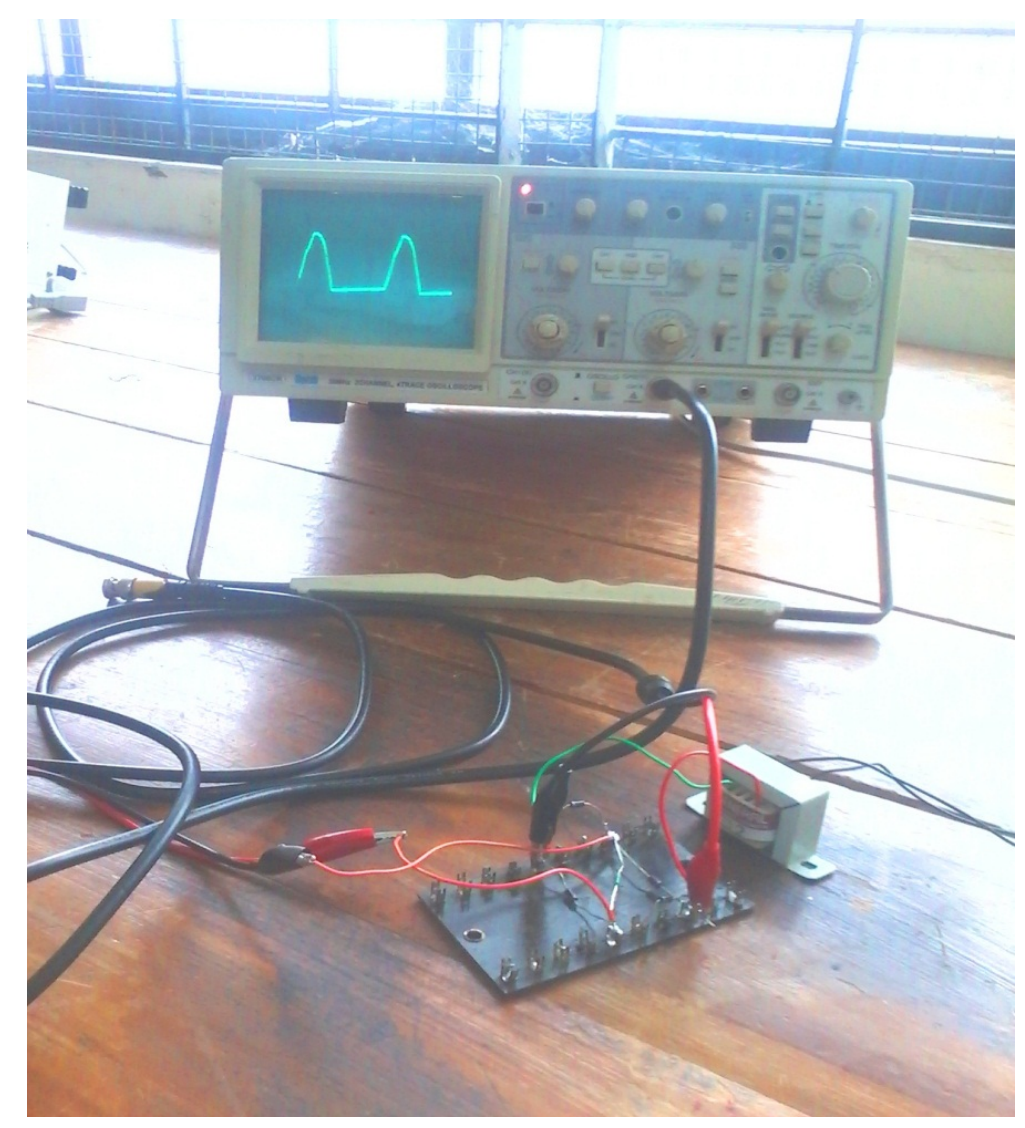

Fig 10. Experimental setup 


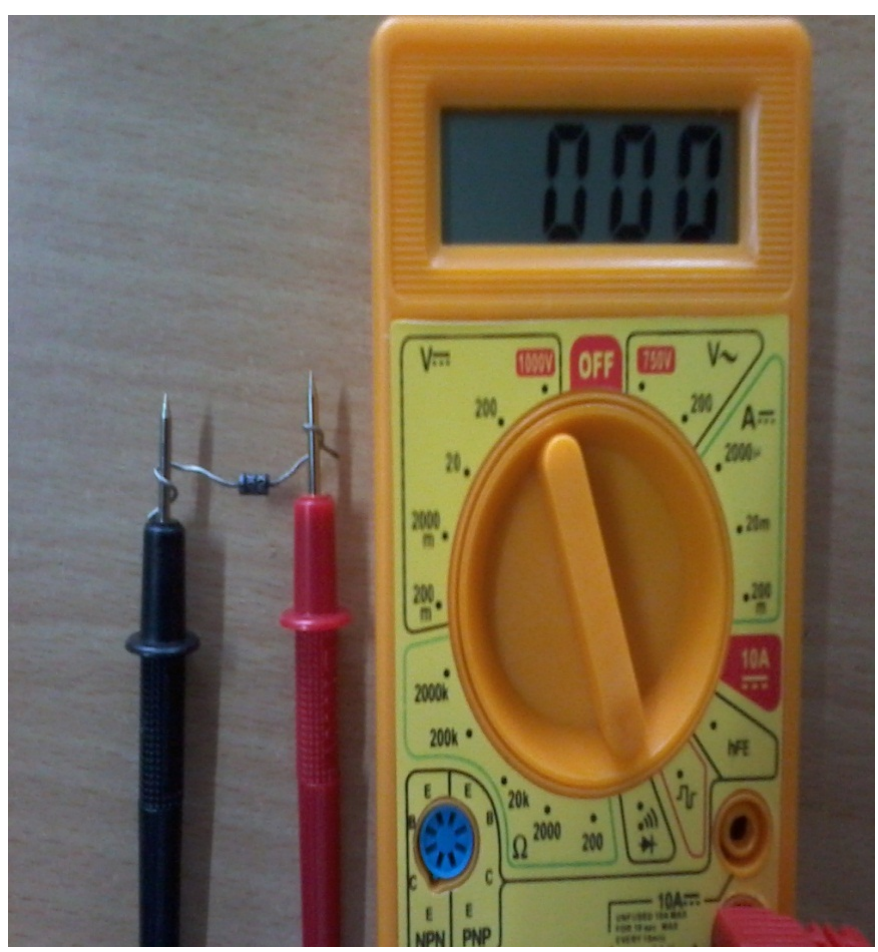

Fig 11. Diode short circuit test

The scope of this study is not limited for experimentation on full bridge rectifier circuit. When component or system level reliability issues are important, computer based simulation tools are helpful to understand the circuit behavior. This will be informative to know the fault tolerant measures needed to consider in hardware implementation phase.

The system specifications are enlisted in Table 1.

Table 1. System specifications

\begin{tabular}{ll}
\hline Parameter & Rating \\
\hline Primary voltage & $230 \mathrm{~V}$ \\
Transformer rating & $0-12 \mathrm{~V}, 200 \mathrm{~mA}$ \\
Output resistance & $120 \Omega$ \\
Peak output voltage & $16.97 \mathrm{~V}$ \\
Peak output current & $0.141 \mathrm{~A}$ \\
Diode & $1 \mathrm{~N} 4007$ \\
\hline
\end{tabular}

For any typical full bridge rectifier circuit with similar specifications, failure rate ${ }^{(15)}$ can be estimated as below ${ }^{(16)}$. Military handbook MIL-HDBK 217F provides database and guidelines for reliability estimation of electronic circuits ${ }^{(15)}$. Part stress analysis method is used to estimate the reliability. This method considers environmental conditions, component constructional details, standard database and electrical stress while computing the component failure rates.

\subsection{Diode failure rate estimation}

$\lambda_{p}=\lambda_{b} \pi_{T} \pi_{S} \pi_{C} \pi_{Q} \pi_{E}$ failures/ $10^{6} \mathrm{hrs}$

where $\lambda_{p}=$ diode failure rate

$\lambda_{b}=$ base failure rate

$\pi_{T}=$ Temperature factor

$\pi_{S}=$ Electrical stress factor

$\pi_{C}=$ Construction factor

$\pi_{Q}=$ Quality factor 
$\pi_{E}=$ Environmental factor

$\lambda_{b}=0.0030$

Power loss across diode is given by ${ }^{(17)}$

$$
\begin{gathered}
P_{\text {Loss_Diode }}=P_{R F \_ \text {Loss }}+P_{V F_{-} \text {Loss }} \\
P_{R F \text { Loss }}=\frac{\left(2 D C_{-} \text {max }+1\right) R_{F} I_{\text {Opeak }}^{2}}{4} \\
\text { Considering } R_{F}=500 \Omega \\
P_{R F L o s s}=4.97 \mathrm{~W} \\
P_{V F L o s s}=\frac{V_{F} I_{O p e a k}}{2} \\
T_{j}=T_{C}+\theta_{j c} P_{\text {DiodeLoss }} \\
P_{\text {DiodeLoss }}=P_{R F L o s s}+P_{V F L o s s}=5.01 \mathrm{~W} \\
0.04935 \mathrm{~W} \\
V_{F}=0.7 \mathrm{~V} \\
\end{gathered}
$$

$T_{C}=35^{\circ} \mathrm{C}$ and $\theta_{j c}=12$

$T_{j}=95.12$

$\pi_{T}=$ Temperature factor $=3.4$

$\pi_{S}=$ Electrical stress factor $=1$ (voltage application)

$\pi_{C}=$ Construction factor $=2$ (non-metallurgical)

$\pi_{Q}=$ Quality factor $=5.5$ ( waived specifications)

$\pi_{E}=$ Environmental factor $=1$ (Ground Benign environment)

Total diode failure rate in presented application is given by

$\lambda_{p}=0.1122$

\subsection{Transformer failure rate estimation}

$\lambda_{p}=\lambda_{b} \pi_{Q} \pi_{E}$ failures $/ 10^{6}$ hours

Base failure rate $\lambda_{b}=0.0028$

$\mathrm{T}_{H S}=\mathrm{T}_{A}+(1.1) \Delta \mathrm{T}$

at $35^{\circ} \mathrm{C}$ and $\Delta \mathrm{T}=4$

$\mathrm{T}_{H S}=39.4$

Quality factor $\pi_{Q}=30$

Environmental factor $\pi_{E}=1$

$\lambda_{p}=$ Part failure rate $=0.084$

$\mathrm{MTTF}=1 / \lambda$

$=20645645 \mathrm{hrs}$ 
Table 2. Component failure rates

\begin{tabular}{llll}
\hline Device & Part failure rate & Number of components & Total failure rate $(\lambda)\left(\right.$ failure $\left./ 10^{6} \mathrm{~h}\right)$ \\
\hline Diode & 0.1122 & 04 & 0.4488 \\
Transformer & 0.084 & 01 & 0.084 \\
Total failure rate & & & 0.5328 \\
\hline
\end{tabular}

\section{Conclusion}

This study showed that the behavior of electric circuits can be analyzed by introducing faulty conditions in CAD based simulation tool. This is easy and economical platform to understand circuit behavior. In initial design phase, circuit operation can be studied under various faulty conditions and systems can be designed to enhance fault tolerance competence. Uses of overrated components, redundancy based fault tolerant circuits are some of the schemes used nowadays to enhance fault tolerance competence. It is also important to develop simulation tools to study structure level faults in semiconductor devices, to analyze environmental effects on the circuit performance etc. Failure rates of components can be calculated using part stress method and reliability handbook to select more fault tolerant component. Considering the faulty nature of power semiconductor devices, it is necessary to focus on reliable circuit designs. Extensive research is needed to form sound data base of components having information like survival time, nature of faults, fault precursors, electrical and thermal effects on component behavior etc.

\section{Acknowledgement}

Authors are thankful to Department of Technology, Shivaji University, and Kolhapur for providing necessary facilities for completion of experimentation.

\section{References}

1) Yang S, Bryant A, Mawby P, Xiang D, Ran L, Tavner P. An industry-based survey of reliability in power electronic converters. IEEE Transactions on Industry Applications. 2011;47(3):1441-1451. Available from: https://dx.doi.org/10.1109/tia.2011.2124436.

2) Song Y, Wang B. Survey on reliability of power electronic systems. IEEE Transactions on Power Electronics. 2013;28(1):591-604. Available from: https://doi.org/10.1109/TPEL.2012.2192503.

3) Wang $\mathrm{H}, \mathrm{Ma} \mathrm{K}$, Blaabjerg F. Design for reliability of power electronic systems. In: and others, editor. IECON. 2012;p. 33-44. Available from: https://doi.org/10.1109/IECON.2012.6388833.

4) Pecht M, Dasgupta A. Physics of failure: an approach to reliable product development. In: and others, editor. Proc. International Integrated Reliability Workshop. ;p. 1-4. Available from: https://doi.org/10.1109/IRWS.1995.493566.

5) Petrone G, Spagnuolo G, Teodorescu R, Veerachary M, Vitelli M. Reliability issues in photovoltaic power processing systems. IEEE Transactions on Industrial Electronics. 2008;55(7):2569-2580. Available from: https://dx.doi.org/10.1109/tie.2008.924016.

6) Chavan SB, Chavan MS. A model based approach for fault diagnosis in converter of photovoltaic systems. In: and others, editor. IEEE Global Conference on Wireless Computing and Networking. 2014;p. 112-115. Available from: https://doi.org/10.1109/GCWCN.2014.7030859.

7) Pei X, Nie S, Chen Y, Kang Y. Open circuit fault diagnosis and fault tolerant strategies for full bridge DC-DC converters. IEEE Transactions on Power Electronics. 2012;27(5):2550-2565. Available from: https://doi.org/10.1109/TPEL.2011.2173589.

8) Ribeiro E, Cardoso AJM, Boccaletti C. Fault-tolerant strategy for a photovoltaic DC-DC converter. IEEE Transactions on Power Electronics. 2013;28(6):3008-3018. Available from: https://dx.doi.org/10.1109/tpel.2012.2226059.

9) Ambusaidi K, Pickert V, Zahawi B. New circuit topology for fault tolerant H-Bridge DC-DC converter. IEEE Transactions on Power Electronics. 2010;25(6):1509-1516. Available from: https://dx.doi.org/10.1109/tpel.2009.2038217.

10) Chao UM, Lee KB, Blaabjerg F. Diagnosis and tolerant strategy of an open switch fault for T-type three level inverter systems. IEEE Transactions on Industry Applications. 2014;50(1):495-508. Available from: https://doi.org/10.1109/TIA.2013.2269531.

11) Airabella AM, Oggier GG, Botalla P, Falco LE, Garcia CA, O G. Open transistors and diodes fault diagnosis strategy for dual active bridge DCDC converter. In: and others, editor. 10th IEEE/IAS International Conference on Industry applications INDUS. 2012;p. 1-6. Available from: https: //doi.org/10.1109/INDUSCON.2012.6453004.

12) Calleja H, Chan F. Reliability: A neglected topic in the power electronics curricula. Journal of Power Electronics. 2010;10(6):660-666. Available from: https://dx.doi.org/10.6113/jpe.2010.10.6.660.

13) Chavan SB, Chavan MS. Power switch faults, diagnosis and tolerant schemes in converters of photovoltaic systems- A review. International Journal of Advanced Research in Electrical, Electronics and Instrumentation Engineering. 2014;03(09):11729-11737. Available from: https://dx.doi.org/10.15662/ ijareeie.2014.0309006.

14) Martínez-Nieto JA, Medrano-Marqués N, Sanz-Pascual MT, Calvo-López B. High-level modeling and simulation tool for sensor conditioning circuit based on artificial neural networks. Sensors. 2019;19(8). Available from: https://dx.doi.org/10.3390/s19081814.

15) Military Handbook-217F (MIL-HDBK 217F). . Available from: https://snebulos.mit.edu/projects/reference/MIL-STD/MIL-HDBK-217F-Notice2.pdf.

16) Chavan SB. Reliability analysis of transformer less DC/DC converter in a photovoltaic system. Acta Electrotehnica. 2016;57(5):579-582. Available from: https://ie.utcluj.ro/files/acta/2016/Number5/paper08_Chavan.pdf. 
17) Kazimierczuk MK. Pulse width modulated DC-DC power converters. and others, editor;Wiley. 2008. Available from: https://onlinelibrary.wiley.com/ doi/book/10.1002/9780470694640. 